\title{
Impact of the COVID-19 Pandemic on Mental Health of the General Population, Students, and Health Care Workers.
}

Sabina Sankhi, Nirmal Raj Marasine*

\section{Author Info:}

'Department of

Pharmaceutical Sciences

Program, School of Health and Allied Sciences, Pokhara University, Pokhara-30, Kaski, Nepal.

\section{Corresponding Author:}

Nirmal Raj Marasine; M.Pharm (Clinical Pharmacy),

Email/Contact:

nirmalmarasine@gmail.com

ORCID ID:

https://orcid.org/0000-00034353-382X

\begin{abstract}
Background: COVID-19 among human is spreading heavily and has brought about a sense of fear, anxiety, depression, and stress around the world. It has resulted in short term as well as long term psychosocial and mental health problems in general population, students and health care workers.

Objective: To summarize the articles related to the mental health aspects of the general population, students, and health care workers impacted by COVID-19 pandemic.

Methods: Published articles on mental health aspects of the general population, students, and health care workers during the COVID-19 outbreak were considered and reviewed.

Results: Increasing actual and suspected cases, conflicting and frustrating news, inadequate and shortage of protective measures, travel bans, isolation, concern of the infection in family, friends or colleagues, the uncertainty of return to the work station, school, college, and universities, and lack of social support are leading to different levels of psychological pressure and increased prevalence of stress, anxiety, depressive symptoms, insomnia, and fear.

Conclusion: Mental health symptoms of stress, anxiety, and depression are the common psychological reactions in the study population. There is a need to improve people's access to mental health services aimed towards providing measures to cope this crisis. For this, rational mental health policies along with direct or digital collaborative network of public, psychiatrists, community volunteers, and governmental and non-governmental organizations are needed. Keywords: COVID-19, Mental health, General population, Students, Health care workers
\end{abstract}

\begin{tabular}{|l} 
QR Code \\
$\begin{array}{l}\text { Scan Me for } \\
\text { Rull Text }\end{array}$ \\
How to cite this article in Vancouver Style?
\end{tabular}




\section{INTRODUCTION}

The Coronavirus Disease 2019 (COVID-19) outbreak started in China in December 2019, and by August 2020, it has spread across the globe, becoming a global threat., 2 Fever, dry cough, and shortness of breath are its major symptoms. ${ }^{2,3}$ The human-to-human transmission of this virus occurs via droplets and direct contact, with an incubation period of 6.4 days and a basic reproduction number of 2.24-3.58. ${ }^{4}$ The World Health Organization (WHO) declared this viral epidemic as a pandemic and announced it as the public health emergency of international concern on 30th January 2020. To date (August 31, 2020), 2,52,54,339 confirmed cases and 8,46,985 death cases attributable to this disease have been reported from 216 countries. ${ }^{5}$ Evidence suggests that the outbreak of this viral disease is associated with psychological distress and symptoms of mental illness. ${ }^{6}$ The development of a vaccine is on the way, and the WHO and public health authorities are acting through public health strategies to control the COVID-19 outbreak. Selfisolation (quarantine) and physical distancing (social distancing) have been enforced in nearly every countries as the most effective measures to protect oneself from this dreadful disease., 8 People failed to follow these strategies during initial stages, and various countries started implementing regional and national lockdowns since January, 2020. They announced both inward and outward travel restrictions, closures of industries, both private and international business agencies, shopping malls, museums, movie theaters, hotels, swimming pools, religious places, and places with large gatherings, including all educational institutions, to fight this pandemic. ${ }^{9}$ However, these are associated with a range of physical effects, such as decreased motor activity, changes in dietary habits, and no exposure to sunlight, along with adverse psychological effects, including stress, fear, anxiety, and depression. ${ }^{10,}{ }^{11}$ As a consequence, it was also expected to increase the levels of loneliness, harmful alcohol, and drug use, and self-harm or suicidal behavior among the general population. ${ }^{12}$

Studies related to mental health about COVID-19 are scarce in Nepal. This study will assist government agencies, healthcare professionals, and other researchers by providing beneficial information that can be used to safeguard the psychological well-being of its people and motivate researchers in Nepal to conduct more studies in the field of pandemics and provide evidencebased information to the public. With the above objectives in mind, the current narrative review was designed to summarize the articles related to the mental health aspects of the general population, students, and health care workers impacted by COVID-19 pandemic.

\section{METHODOLOGY}

The current article is a narrative review of the literature relevant to the impact of the COVID-19 pandemic on the mental health of the general population, students, and health care workers. The search was limited to English language studies published in journals from December, 2019, till June, 2020. A search of the PubMed and Google Scholar electronic databases was undertaken using the search terms: COVID-19, novel coronavirus, anxiety, depression, stress, fear, general population, students, international students, health care workers, COVID-19 effects, COVID-19 and mental health, and psychological effects of COVID. We also included articles listed in the authors' reference lists and those listed in other narrative reviews. Studies were selected based on relevance. Full articles on those studies that were deemed relevant to our study title were fully reviewed, and irrelevant studies were eliminated.

A total of 1124 citations were retrieved, of which 87 were eligible full-text studies assessed. On reviewing these, 37 were excluded: 5 because they were in a language other than the English, 9 because they were review articles, and 23 because psychiatric symptoms relevant to COVID-19 were not reported and especially dealt with clinical characteristics, drug therapy, public health, and preventive measures. The remaining 50 studies were included in this narrative review. These 50 studies consisted of original research, letters to the editor, journal preproofs, and editorials or commentary related to COVID-19 and mental health. Our study outcomes were various mental health symptoms, such as stress, anxiety, depression, and fear, in the general population, students, and health care workers relevant to the COVID-19 pandemic. Figure 1 illustrates the study selection procedure.

\section{RESULTS}

A total of 50 studies were included in our narrative review, and only 9 original articles were reviewed. All nine studies were online and cross-sectional surveys. The majority (5/9) of them were from China, two publications from India, and one each from Iran and Denmark. A summary of the studies included in this narrative review is presented in Table 1. 

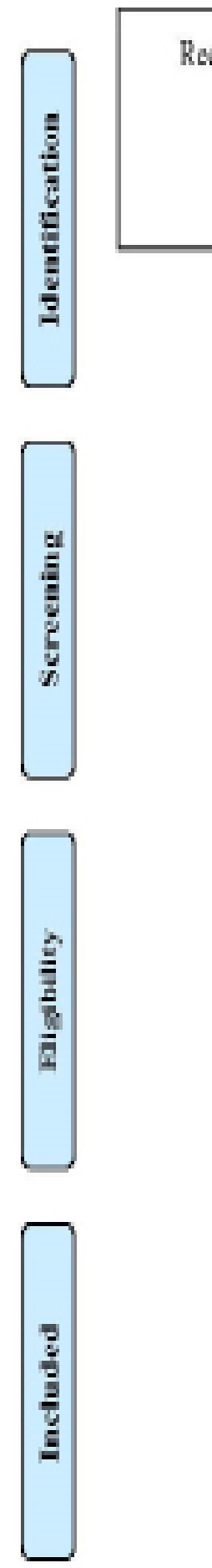

Reconds identifisd though relevant Barchs $(0=1100)$ 


\begin{tabular}{|c|c|c|c|}
\hline Study & Objective & Methods & Major findings \\
\hline $\begin{array}{l}\text { Kazmi et al } \\
(2020)^{14}\end{array}$ & $\begin{array}{l}\text { To assess the mental health of } \\
\text { individuals during lockdown } \\
\text { amid the Covid-19 pandemic } \\
\text { in India. }\end{array}$ & $\begin{array}{l}\text { Online survey } \\
\text { Study population: general } \\
\text { population ( } n-1000) \\
\text { Study instrument: Depression } \\
\text { Anxiety and Stress Scale (DASS- } \\
21) \text {, to assess Depression, Anxiety, } \\
\text { and Stress. }\end{array}$ & $\begin{array}{l}50 \% \text { of severe stress was seen in the } 21-25 \\
\text { years age group and women. } \\
\text { Stress and anxiety were high in } 21-25 \text { years } \\
\text { age group and women, whereas depression } \\
\text { was high in the } 15-35 \text { year age group, and } \\
\text { mostly in men. Unemployed were most } \\
\text { affected than employed. }\end{array}$ \\
\hline
\end{tabular}

and Stress.

Cross-sectional online survey

Study population: general

To establish the prevalence of psychiatric symptoms and

Wang et al identify risk and protective factors contributing to psychological stress.

population $(n=1210)$

Study instrument: Impact of Event Scale-Revised (IES-R), and Depression, Anxiety, and Stress Scale (DASS-21) used to assess the psychological impact and mental health status.

\begin{tabular}{|l|l|}
\hline $\begin{array}{l}\text { Roy et al } \\
\mathbf{( 2 0 2 0 )}^{16}\end{array}$ & $\begin{array}{l}\text { To assess the knowledge, } \\
\text { attitude, anxiety experience, } \\
\text { and perceived mental } \\
\text { healthcare need among } \\
\text { the adult Indian population } \\
\text { during the COVID-19 } \\
\text { pandemic. }\end{array}$ \\
\hline $\begin{array}{l}\text { Sønderskov et } \\
\text { al (2020)17 }\end{array}$ & $\begin{array}{l}\text { To measure the level of } \\
\text { psychological well-being } \\
\text { in Denmark during the } \\
\text { COVID-19 pandemic }\end{array}$ \\
\hline
\end{tabular}

\begin{tabular}{|c|c|}
\hline $\begin{array}{l}\text { Moghanibashi } \\
\text { Mansourieh, } \\
\text { (2020) }^{18}\end{array}$ & $\begin{array}{l}\text { To assess the general } \\
\text { population anxiety level } \\
\text { during COVID- } 19 \text { spread. }\end{array}$ \\
\hline
\end{tabular}

Cross-sectional online survey Study population: general population $(n=662)$ Study instrument: online selfreported questionnaire

\section{Online survey}

Study population: general

population $(n=2458)$

Study instrument: WHO-5 well-

being scale

Online survey

Study population: general

population $(n=10,754)$

Study instrument: Depression,

Anxiety and Stress Scale (DASS 21)

$16.5 \%$ of people had moderate to severe depressive symptoms, $28.8 \%$ had moderate to severe anxiety symptoms, and $8.1 \%$ had moderate to severe stress. COVID-19 infection and distress related social media in $12 \%, 40 \%$, and $41 \%$ participants respectively. About $72 \%$ were worried about themselves and their near ones.

The psychological well-being of the Danish general population was affected negatively by the COVID-19 pandemic. Females were more affected than men.

Anxiety level was severe in $9.3 \%$ and very severe in $9.8 \%$

The level of anxiety was significantly higher $(P<0.001)$ in female, $21-40$ years age group highly educated people, those who followed coronavirus news, and who had at least one family member with COVID-19.

Web-based cross-sectional study

Study population: general

population $(n=7236)$

Study instrument: GAD-7

burden of the Chinese

Huang and population during the

Zhao, (2020) ${ }^{19}$ COVID-19 pandemic, and

(Generalized Anxiety Disorder-7)

scale, Center for Epidemiology

to explore the potential Scale for Depression (CES-D), and influence factors.

PSQI (Pittsburgh Sleep Quality Index) scale for assessing sleep guality.

Cross-sectional survey

Study population: college

students $(n=7143)$

Study instrument: 7-item

Generalized Anxiety Disorder

Scale (GAD-7)

Cross-sectional survey

Study population: medical and administrative staffs $(n=2299)$

Study instrument: Hamilton

Anxiety Scale (HAMA) and the Hamilton Depression Scale (HAMD)

status of the medical

$\mathbf{( 2 0 2 0 )}^{21}$ workforce during the

COVID-19 pandemic.

Cross-sectional, hospital-based survey

Study population: health care workers $(n=1257)$

Study instrument: 7-item

Generalized Anxiety Disorder

(GAD-7) scale, 7-item Insomnia

Severity Index (ISI), 9-item Patient

Health

Questionnaire (PHQ-9), and 22-

item Impact of Event

Scale-Revised (IES-R)

Prevalence of anxiety disorders, depressive symptoms, sleep quality: $35.1 \%, 20.1 \%$,

$18.2 \%$, respectively. Younger people and healthcare workers $(31.1 \%)$ were more prone to develop anxiety, depression, and poor sleep quality $(P<0.001)$

$21.3 \%$ of students had mild anxiety, $2.7 \%$ had moderate, and $0.9 \%$ had severe anxiety.

Medical staff who came in close contact with infected patients of respiratory emergency, infectious disease and ICU were 1.4 times more likely to feel fear, twice more likely to suffer anxiety and depression than administrative staff.

Of all the participants, 50.4\% reported symptoms of depression, $44.6 \%$ reported anxiety, $34.0 \%$ reported insomnia, and $71.5 \%$ reported distress, respectively. 


\section{DISCUSSION}

\section{Impact on the general population}

Epidemics and pandemics are periodic phenomena whose impacts are often intense and may even adversely affect the well-being of the general population. ${ }^{15}$ The increasing number of patients, suspected cases, and affected countries have contributed in making people more worried and anxious about being infected with COVID-19.6, 13-18 Since the onset of COVID-19, the use of masks and sanitizers has increased, leading to their exhaustion in the market.22 Some degree of nervousness resides in public due to the unavailability of protective measures. Likewise, media also influences the mental well-being of people and can add to the level of mental symptoms. ${ }^{23}$ Fear of unknown factors leads to increased anxiety levels in both normal and pre-existing mental patients. ${ }^{24}$ Therefore, thorough knowledge of specific issues plays an important role in keeping oneself positive and motivated in every havoc condition. The increased curiosity of people about the global status of a pandemic and the discovery of treatment measures specially the vaccination in progress, make people seek increasingly more event-related information. In scarce information from reliable sources, misleading and conflicting information on social sites starts to create room for stress, anxiety, fear, and depression in people. ${ }^{25}$ Evidence suggests that "the more people follow COVID-19 news, the more anxious they become". ${ }^{\prime 17,26,27}$ The constant exposure to disappointing and exaggerated information on COVID-19 makes people more prone to develop higher levels of stress and anxiety. ${ }^{17}$

Many parts of the world that contribute largely to the global economy have halted their service and products due to this pandemic. As a result, the global supply chain has been broken, extremely affecting the global economy. ${ }^{28}$ Although many company employees are working from home in this pandemic, it even has financial disadvantages..$^{15}$ In contrast, many families have lost their source of income in this outbreak, which has added more problems in their livelihood. The uncertain time of returning to work and infections associated with public transportation further exacerbated fear, stress, anxiety, and depression in people of poor economic status. ${ }^{19}, 29$ Similarly, additional changes such as isolation, social distancing, restriction to travel, worry about health conditions of family, friends or colleagues, and any infected family members or people from the same community are also likely to adversely affect the mental health of the public. ${ }^{30}$

\section{Impact on students}

Where the whole world is facing the bad consequence of this pandemic, students alone cannot remain untouched. To reduce the spread of COVID-19 among young and adult populations, many countries have prompted the closures of schools, colleges, universities, and other educational institutions, which no doubt has a specific impact on the educational growth of students. ${ }^{19,} 31,32$ About $91 \%$ of the world's student population have been negatively impacted from the nationwide closures of educational institutes. ${ }^{33}$ Continuous spread of COVID-19, home confinement, strict isolation measures are associated with anxiety in students which is attributable to hindrance in their education, physical activities and socialization opportunities. ${ }^{34-37}$ Absence of structured routine of the school, colleges and universities for a long time results in disruption of timetable making students lethargy with lack of innovative ideas in academic and extracurricular activities.

Despite the closures of educational institutes, many schools, colleges, and universities are managing to provide online classes to their students to continue their course and learning process. In the present situation, computers and the internet at home are in high demand from the students, which is becoming a stressor for low-income families, as this way of learning has become expensive for them in this crisis. ${ }^{38}$ Children from such an economic background develop anxiety as they fear not being able to cover their course. The students who are to be graduated this year are also affected by COVID-19 due to interruptions in the assessment of their final part of the studies. They are likely to develop anxiety with the likelihood of their late graduation and a long stay at home in their career development phase. The uncertainty in the reopening of educational institutes, cancellation of examinations and academic events are other stressors for students. ${ }^{15,} 33$ Likewise, the concern about post-pandemic effect in employment opportunities might be responsible for depression in graduate students. Moreover, international students who are staying far from their parents/ loved ones are at a higher risk of developing mental problems such as anxiety and depression. ${ }^{39}$ They are not only worried about their health and education but also have a huge concern for the well-being of their families. ${ }^{39,40}$ Students who managed to go home in this pandemic stress being unable to return to their educational institutions 
for the completion of their studies.

\section{Impact on health care workers}

The world has faced a nightmare, as many health care workers have lost their lives in their battle against the coronavirus pandemic. ${ }^{13}$ During this harsh situation, where the world is facing shutdown or slowdown in daily activities and people are encouraged to obey social distancing to reduce interpersonal contacts, health care workers go in the opposite direction. ${ }^{20,41}$ Health care workers are frontline professionals who are at a higher risk of developing psychological distress and other mental health problems, as they are directly involved in the diagnosis, treatment, and care of infected patients. ${ }^{21}$, 42 Health care workers around the globe are dealing with a high risk of infection, inadequate protection, overwork, frustration, and negative thought patients. On the other side, health workers are staying in isolation, discrimination, lack of contact with their family members, lack of specific drugs, and feelings of being inadequately supported, ${ }^{43}$ which has become the major cause for stress, anxiety, insomnia, depressive symptoms, anger, and fear in them. ${ }^{21,44}$ These psychosocial conditions not only affects health care workers' understanding, focusing, and decision-making ability, which is essential for fighting against COVID-19, but could also have a lasting effect on their overall wellbeing. ${ }^{43,45}$ Despite the stressful day at work they cannot spend time with their family, they cannot hold their children. ${ }^{46}$ They fear autoinoculation and the possibility of spreading the virus to their families, friends, and colleagues. ${ }^{47}$ This forces them to isolate themselves from their family, change their habit, and narrow their social network, resulting in different levels of psychological pressure. ${ }^{47,48}$ This triggers the feeling of helplessness and loneliness, leading to a series of dysphoric emotional states such as stress, irritation, physical and mental fatigue, and despair. ${ }^{48}$ Health care workers involved directly in the care of infected persons also have to suffer stigma. Hence, an increase in the number of confirmed and suspected cases increases pressure on them. ${ }^{49}$ During this pandemic, a trend is popular, that is, giving the tag of superheroes to health care professionals. This in one way adds value to their profession but in the other way increases mental pressure to them because superheroes never fail and never give up or never get sick. ${ }^{50}$ In the case of any mistake, instead of emotional support and encouragement, the media exaggerates it and makes it more sensational than an actual event. This type of moral suffering leads to the collapse of the health system and prevents health professionals from making effective decisions because of fear and lowered self-esteem in them to face such suffering or due to hierarchical pressure, organizational problems, and lack of resources. ${ }^{50}$

\section{Limitations}

The literatures for this narrative review were selected when the world was facing global lockdown and this mental health issues was new. Only few studies were reported from the world. Likewise, in our review, we were unable to focus on the management strategies targeted towards the study population. Last but not the least, the short study period and the only use of electronic databases might have increased the probability of missing relevant studies on the mental health care of general population, students and health workers.

\section{CONCLUSION AND RECOMMENDATIONS}

Although the COVID-19 outbreak started in Wuhan, China, it has now become a global public health issue. Increasing actual and suspected cases, conflicting and frustrating news, inadequate and shortage of protective measures, travel bans, isolation, concern of the infection in family, friends or colleagues, the uncertainty of return to the work station, school, college, and universities, and lack of social support are leading to different levels of psychological pressure and increased prevalence of stress, anxiety, depressive symptoms, insomnia, and fear in the general public, students, and health care workers worldwide.

This review highlights the need to improve people's access to mental health services either through face to face interaction or online approach. This is possible only through the collaboration of public, psychiatrists, community volunteers, and governmental or non-governmental organizations. To prevent during and post-pandemic mental health issues, approach like 'tele mental health service' should be implemented and made accessible to the public at large. Time-limited and culturally sensitive mental health interventions should be made the focal point of health care system and policymakers to fulfill the mental health needs of every public. Likewise, there is a need for more evidence-based research from other affected countries, particularly in vulnerable populations such as children and adolescents, people of lower socioeconomic status, and those residing in rural areas, focusing the countries with less developed mental health infrastructures. So that the valid strategies can be 
developed at both the individual and population levels, to eradicate this pandemic and outbreak of similar types in the near future.

\section{Acknowledgment}

We acknowledge all the authors of the retrieved studies.

\section{Declaration of conflicting interests}

The authors declare that there is no conflicts of interest to the research, authorship, and/or publication of this review.

\section{REFERENCES}

1. Spina S, Marrazzo F, Migliari M, Stucchi R, Sforza A, Fumagalli R. The response of Milan's Emergency Medical System to the COVID-19 outbreak in Italy. The Lancet. 2020; 395(10227): e49-50. https://doi.org/10.1016/ S0140-6736(20)30493-1] Weblink $\downarrow$ Google Scholar

2. Holshue ML, DeBolt C, Lindquist S, Lofy KH, Wiesman J, Bruce H, Spitters C, Ericson K, Wilkerson S, Tural A, Diaz G. First case of 2019 novel coronavirus in the United States. New England Journal of Medicine. 2020. https:// doi.org/10.1056/NEJMoa2001191| Google Scholar

3. Guan WJ, Ni ZY, Hu Y, Liang WH, Ou CQ, He JX, Liu L, Shan $\mathrm{H}$, Lei $\mathrm{CL}$, Hui DS, Du B. Clinical characteristics of coronavirus disease 2019 in China. New England journal of medicine. 2020; 382(18):1708-20. https:// doi.org/10.1056/NEJMoa2002032 | Google Scholar

4. Lai CC, Shih TP, Ko WC, Tang HJ, Hsueh PR. Severe acute respiratory syndrome coronavirus 2 (SARSCoV-2) and corona virus disease-2019 (COVID-19): the epidemic and the challenges. International journal of antimicrobial agents. 2020:105924. https://doi.org/10.1016/j.ijantimicag.2020.105924 Elsevier | Google Scholar

5. World Health Organization. Coronavirus disease (COVID-19) Dashboard. Weblink (accessed September 12, 2020).

6. Bao Y, Sun Y, Meng S, Shi J, Lu L. 2019-nCoV epidemic: address mental health care to empower society. The Lancet. 2020; 395(10224):e37-8. https:// doi.org/10.1016/S0140-6736(20)30309-3 | Weblink

7. World Health Organization, 2020. Advice for public: Coronavirus disease 2019 (COVID-19). Weblink (accessed September 12, 2020).

8. Usher K, Bhullar N, Jackson D. Life in the pandemic: Social isolation and mental health. Journal of Clinical Nursing. 2020. https://doi.org/10.1111/jocn.15290| Google Scholarl Weblink

9. Liu W, Zhang Q, Chen J, Xiang R, Song H, Shu S, Chen L, Liang L, Zhou J, You L, Wu P. Detection of Covid-19 in children in early January 2020 in Wuhan, China. New England Journal of Medicine. 2020; 382(14):
1370-1. https://doi.org./10.1056/NEJMc2003717 Google Scholar | Weblink

10. LippiG, Henry BM, Sanchis-GomarF. Physical inactivity and cardiovascular disease at the time of coronavirus disease 2019 (COVID-19). European Journal of Preventive Cardiology. 2020: 2047487320916823. https://doi.org/10.1177/2047487320916823 PubMed | Google Scholar

11. Ahmed MZ, Ahmed O, Aibao Z, Hanbin S, Siyu L, Ahmad A. Epidemic of COVID-19 in China and associated Psychological Problems. Asian journal of psychiatry. 2020: 102092. https://doi.org/10.1016/j.ajp.2020.102092 | Elsevier | Google Scholar

12. Mukhtar S. Pakistanis' mental health during the COVID-19. Asian Journal of Psychiatry. 2020. https:// doi.org/10.1016/j.ajp.2020.102127 | PMC | Google Scholar

13. Kazmi SS, Hasan K, Talib S, Saxena S. COVID-19 and Lockdwon: A Study on the Impact on Mental Health. Available at SSRN 3577515. 2020. http://dx.xoi. org/10.2139/ssrn.3577515 | Google Scholar

14. Wang C, Pan R, Wan $X$, Tan $Y, X u$ L, Ho CS, Ho RC. Immediate psychological responses and associated factors during the initial stage of the 2019 coronavirus disease (COVID-19) epidemic among the general population in China. International journal of environmental research and public health. 2020; 17(5):1729. https://doi.org/10.3390/ijerph17051729 $\downarrow$ Google Scholar

15. Roy D, Tripathy S, Kar SK, Sharma N, Verma SK, Kaushal V. Study of knowledge, attitude, anxiety \& perceived mental healthcare need in Indian population during COVID-19 pandemic. Asian Journal of Psychiatry. 2020: 102083. https://doi.org/10.1016/j.ajp.2020.102083 | Elsevier | Google Scholar

16. Sønderskov KM, Dinesen PT, Santini ZI, Østergaard SD. The depressive state of Denmark during the COVID-19 pandemic. Acta neuropsychiatrica. 2020: 1-3. https://doi.org/10.1017/neu.2020.15 | Google Scholar | Weblink

17. Moghanibashi-Mansourieh A. Assessing the anxiety level of Iranian general population during COVID-19 outbreak. Asian Journal of Psychiatry. 2020: 102076. https://doi.org/10.1016/j.ajp.2020.102076 | Elsevier | Google Scholar

18. Huang $\mathrm{Y}$, Zhao N. Chinese mental health burden during the COVID-19 pandemic. Asian Journal of Psychiatry. 2020; 51: 102052. https://doi. org/10.1016/j.ajp.2020.102052 | PMC | Google Scholar

19. Cao W, Fang Z, Hou G, Han M, Xu X, Dong J, Zheng J. The psychological impact of the COVID-19 epidemic on college students in China. Psychiatry research. 2020: 112934. https://doi.org/10.1016/i psychres.2020.112934 | Elsevier | Google Scholar 
20. Lu W, Wang $H$, Lin $Y$, Li L. Psychological status of medical workforce during the COVID-19 pandemic: A cross-sectional study. Psychiatry research. 2020: 112936. https://doi.org/10.1016/j. psychres.2020.112936 | Elsevier | Google Scholar

21. Lai J, Ma S, Wang Y, Cai Z, Hu J, Wei N, Wu J, Du $\mathrm{H}$, Chen $\mathrm{T}$, Li R, Tan H. Factors associated with mental health outcomes among health care workers exposed to coronavirus disease 2019. JAMA network open. 2020; 3(3):e203976-. https://doi.org/10.1001/ jamanetworkopen.2020.3976 | Google Scholar

22. Feng S, Shen C, Xia N, Song W, Fan M, Cowling BJ. Rational use of face masks in the COVID-19 pandemic. The Lancet Respiratory Medicine. 2020; 8(5):4346. https://doi.org/10.1016/S2213-2600(20)30134-X | Weblink

23. Ayittey FK, Ayittey MK, Chiwero NB, Kamasah JS, Dzuvor C. Economic impacts of Wuhan 2019$\mathrm{nCoV}$ on China and the world. Journal of Medical Virology. 2020; 92(5):473-5. https://doi.org/10.1002/ jmv.25706 | Google Scholar | Weblink

24. Mowbray H. In Beijing, coronavirus 2019-nCoV has created a siege mentality. Bmj. 2020; 368. https:// doi.org/10.1136/bmj.m516 | GoogleScholar

25. Jung SJ, Jun JY. Mental health and psychological intervention amid COVID-19 outbreak: perspectives from South Korea. Yonsei Medical Journal. 2020; 61(4):271-2. https://doi.org/10.3349/ ymj.2020.61.4.271 | PMC | Google Scholar

26. Asmundson GJ, Taylor S. Coronaphobia: Fear and the 2019-nCoV outbreak. Journal of anxiety disorders.

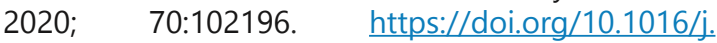
janxdis.2020.102196 | PMC | Google Scholar

27. Asmundson GJ, Taylor S. How health anxiety influences responses to viral outbreaks like COVID-19: What all decision-makers, health authorities, and health care professionals need to know. Journal of Anxiety Disorders. 2020; 71:102211-. https://doi. org/10.1016/j.janxdis.2020.102211 | PMC | Google Scholar

28. Ebrahim SH, Ahmed QA, Gozzer E, Schlagenhauf $\mathrm{P}$ Memish ZA. Covid-19 and community mitigation strategies in a pandemic. BMJ 368. https://doi. org/10.1136/bmj.m1066 | Google Scholar

29. Tian F, Li H, Tian S, Yang J, Shao J, Tian C. Psychological symptoms of ordinary Chinese citizens based on SCL-90 during the level I emergency response to COVID-19. Psychiatry Research. 2020:112992. https://doi.org/10.1016/j.psychres.2020.112992 Elsevier | Google Scholar

30. Banerjee D. The COVID-19 outbreak: Crucial role the psychiatrists can play. Asian journal of psychiatry. 2020; 50: 102014. https://doi. org/10.1016/j.ajp.2020.102014 LPM | Google Scholar
31. Chen S, Yang J, Yang W, Wang C, Bärnighausen T. COVID-19 control in China during mass population movements at New Year. The Lancet. 2020; 395(10226):764-6. https://doi.org/10.1016/S01406736(20)30421-9 | Google Scholar | Weblink

32. Gewin V. Five tips for moving teaching online as COVID-19 takes hold. Nature. 2020; 580(7802):2956. DOI: 10.1038/d41586-020-00896-7 | Google Scholar

33. Lee J. Mental health effects of school closures during COVID-19. The Lancet Child \& Adolescent Health. 2020; 4(6):421. https://doi.org/10.1016/S2352-4642(20)301097) Google Scholar| PMC

34. Jiao WY, Wang LN, Liu J, Fang SF, Jiao FY, PettoelloMantovani M, Somekh E. Behavioral and emotional disorders in children during the COVID-19 epidemic. The journal of Pediatrics. 2020; 221:264. https://doi. org/10.1016/j.jpeds.2020.03.013 | PMC

35. Xiao C. A novel approach of consultation on 2019 novel coronavirus (COVID-19)-related psychological and mental problems: structured letter therapy. Psychiatry investigation. 2020; 17(2):175. https://doi.org/10.30773/ pi.2020.0047 | PMC | Google Scholar

36. Kmietowicz Z. Rules on isolation rooms for suspected covid-19 cases in GP surgeries to be relaxed. BMJ 368. https://doi.org/10.1136/bmj.m707 | Weblink

37. Tang B, Bragazzi NL, Li Q, Tang S, Xiao Y, Wu J. An updated estimation of the risk of transmission of the novel coronavirus (2019-nCov). Infectious disease modelling. 2020; 5:248-55. https://doi.org/10.1016/j. idm.2020.02.001 | Google Scholar

38. Van Lancker W, Parolin Z. COVID-19, school closures, and child poverty: a social crisis in the making. The Lancet Public Health. 2020; 5(5):e243-4. https://doi. org/10.1016/S2468-2667(20)30084-0 | Weblink

39. Zhai $Y, D u X$. Mental health care for international Chinese students affected by the COVID-19 outbreak. The Lancet Psychiatry. 2020; 7(4):e22. https://doi.org/10.1016/S2215-0366(20)30089-4 Google Scholar

40. Sood S. Psychological effects of the Coronavirus disease-2019 pandemic. Research \& Humanities in Medical Education. 2020; 7:23-6. Weblink

41. Wilder-Smith A, Freedman DO. Isolation, quarantine, social distancing and community containment: pivotal role for old-style public health measures in the novel coronavirus (2019-nCoV) outbreak. Journal of travel medicine. 2020; 27(2):taaa020. https://doi org/10.1093/jtm/taaa020 | Google Scholar

42. Zhang $W R$, Wang $K$, Yin $L$, Zhao WF, Xue $Q$, Peng $M$, Min BQ, Tian Q, Leng HX, Du JL, Chang H. Mental health and psychosocial problems of medical health workers during the COVID-19 epidemic in China. Psychotherapy and psychosomatics. 2020:19. https://doi.org/10.1159/000507639| PubMed 
Google Scholar

43. Kang $L$, Li Y, Hu S, Chen M, Yang C, Yang BX, Wang $Y, H u$ J, Lai J, Ma X, Chen J. The mental health of medical workers in Wuhan, China dealing with the 2019 novel coronavirus. The Lancet Psychiatry. 2020; 7(3):e14. https://doi.org/10.1016/S22150366(20)30047-X | Google Scholar

44. Cai W, Lian B, Song X, Hou T, Deng G, Li H. A crosssectional study on mental health among health care workers during the outbreak of Corona Virus Disease 2019. Asian Journal of Psychiatry. 2020; 51: 102111. https://doi.org/10.1016/j.ajp.2020.102111 PMC | Google Scholar

45. Chen $Q$, Liang M, Li Y, Guo J, Fei D, Wang L, He L, Sheng C, Cai Y, Li X, Wang J. Mental health care for medical staff in China during the COVID-19 outbreak. The Lancet Psychiatry. 2020; 7(4): e15-6. https://doi.org/10.1016/S2215-0366(20)30078-X | Google Scholar

46. Wang W, Tang J, Wei F. Updated understanding of the outbreak of 2019 novel coronavirus (2019-nCoV) in Wuhan, China. Journal of medical virology. 2020; 92(4):441-7. https://doi.org/10.1002/jmv.25689 | Google Scholar | Weblink

47. Xiang YT, Yang Y, Li W, Zhang L, Zhang Q, Cheung T, $\mathrm{Ng}$ CH. Timely mental health care for the 2019 novel coronavirus outbreak is urgently needed. The Lancet Psychiatry. 2020; 7(3):228-9. https://doi.org/10.1016/ S2215-0366(20)30046-8 | Google Scholar

48. Huang JZ, Han MF, Luo TD, Ren AK, Zhou XP. Mental health survey of 230 medical staff in a tertiary infectious disease hospital for COVID-19. Zhonghua lao dong wei sheng zhi ye bing za zhi= Chinese journal of industrial hygiene and occupational diseases. 2020;38: E001. https:// doi.org/10.3760/cma.j.cn121094-20200219-00063 Google Scholar | Weblink

49. Rana W, Mukhtar S, Mukhtar S. Mental health of medical workers in Pakistan during the pandemic COVID-19 outbreak. Asian journal of psychiatry. 2020; 51:102080. $\quad$ https://doi.org/10.1016/j. ajp.2020.102080 | PMC | Google Scholar

50. Ornell F, Halpern SC, Kessler FH, Narvaez JC. The impact of the COVID-19 pandemic on the mental health of healthcare professionals. Public Health Notebooks. 2020; 36: e00063520. https://doi.org/10.1590/0102$\underline{311 \times 00063520}$ | Google Scholar 